\title{
Políticas sociales y participación en México. El caso del programa Comedores Comunitarios
}

\author{
Luis Rodríguez Castillo•
}

\section{Introito}

Las Ciencias Políticas tomaron como una importante rama de sus reflexiones esa área que hoy se confunde fácilmente como su único objeto de investigación: las políticas públicas. Entre ellas, las políticas sociales han llamado fuertemente la atención desde otras disciplinas de las Ciencias Sociales, sobre todo desde el momento en que los gobiernos pusieron en marcha en las diferentes fases de las políticas los consejos consultivos en los que se integraban miembros de la academia, así como los consejos sociales que idealmente deberían tener un papel protagónico en la evaluación de los programas sociales. No obstante, las más de las veces hacemos un abordaje de manera fragmentaria sobre alguna de sus dimensiones, y sin un claro sustrato conceptual que guíe tanto nuestra documentación como las reflexiones.

- Universidad Nacional Autónoma de México, CIMSUR. Orcid: 0000 0002-4887-823X I lurodri@unam.mx.

El libro de Manuel Martínez Políticas sociales y participación en México. El caso del programa Comedores Comunitarios en el cual,

Fecha de recepción: 23 de octubre de 2019. Fecha de aceptación: 2 de junio de 2020 .

Martínez Espinoza, Manuel Ignacio (2019). Políticas sociales y participación en México. El caso del programa Comedores Comunitarios. México: CESMECA, UNICACH, ODEMCA, CONACYT, Miguel Ángel Porrúa, Colección Las Ciencias Sociales, Cuarta Década, 399 Pp., ISBN 978607-524-300-9. 
en efecto, decide concentrar la atención en un componente de un programa - la participación-, pareciera invitarnos a pensar que seguirá los mismos derroteros enunciados con antelación. No obstante, esta obra confeccionada en cuatro largos capítulos, a los que se suman la introducción y conclusiones, presenta una diferencia sustancial. Comienzo por señalar que, al aplicar el adjetivo "largos", no se trata de una queja sino, por el contrario, pretendo hacer un halago, ya que son largos y de difícil síntesis, no por la extensión sino por la riqueza del contenido.

La adjetivación quiere destacar una minuciosidad en el análisis del dato, la sistematicidad al presentarlo y también su generosidad al compartirlo, sumado a que encontramos a este tenor flechas del tiempo, categorizaciones, tablas, diagramas, resúmenes de características, tipologías, entre otros. Asimismo, el lector encontrará el debate conceptual y los cambios históricos que han acaecido en dichas políticas y en el componente seleccionado. Es decir, tenemos un fundamento epistemológico deductivo —al más puro estilo Sherlock Holmes, al que el propio autor cita- y una orientación teórico-metodológica coherente y congruente.

\section{El contenido de la obra}

La Introducción rebasa los usos comunes de ser una breve exposición del contenido. Es un ejercicio de honestidad intelectual. Marca los inicios y las transformaciones que sufrió la investigación, así como su devenir. Y extraigo una declaración que vale la pena compartir: "el análisis ya no consistiría en adecuar la información obtenida al modelo analítico, sino en readecuar el esquema de análisis a los hallazgos de trabajo de campo" (p. 15).

Por su parte el capítulo I, Política social: definiciones, variaciones y modalidades del repertorio de intervenciones políticas en el ámbito de lo social, se inicia con la expo- 
sición de la definición de política y sus difíciles rumbos desde la filosofía política, para poder abordar la definición de su objeto de investigación: la política social. Es decir, realiza un recorrido histórico de los principales derroteros conceptuales. Su exploración es amplia y contabilizada; en su cuadro resumen llega al nada despreciable número de cuarenta definiciones de diferentes autores. Sin miedo a decirlo y citando a Merino, afirma que la política social se trata de una orientación normativa; es decir, la definición de problemas públicos desde una posición de poder, por lo que disponen de un factor coercitivo y legal que, a la vez que interviene en lo social, entraña una afirmación de valores.

$\mathrm{Al}$ revisar el concepto de política social en el mundo recurre a Lucas y Donati para hacer una observación crítica de relevancia, al recordarnos que política social y Estado de Bienestar son dos conceptos que no deben confundirse, pues debemos dejar atrás esa concepción anquilosada que nos decía que el objeto que definía al Estado del Bienestar era la implementación de un sistema de bienestar social; estos han cambiado y existen aún en el actual Estado tildado de neoliberal. Y desde este primer capítulo apunta a su objeto de investigación, al observar que en el marco de crisis y reformas del último cuarto del siglo xx surgen las "reformulaciones sustentadas en la eficiencia, la legitimidad y la democratización [del Estado] en que (...) la participación ciudadana comenzará a integrarse como uno de los fundamentos constitutivos de las políticas sociales (p. 71).

El siguiente acápite, Genealogía y evaluación de la política social en México, sigue la misma lógica del capítulo anterior, al andar sobre la presentación sociohistórica de las transformaciones de la política social, y muestra las diferentes periodizaciones que se han ensayado. El autor aporta la propia al señalar un gran periodo que va de la constitución a la transición (1917-1988) y la implementa- 
ción de los nuevos modelos (1988-...). A este último le pasa revista a partir de la subperiodización sexenal.

Acerca del primer bloque devela que, si bien el constitucionalismo sienta las bases legales, las acciones de intervención se verán claramente con el proceso de consolidación del Estado mexicano posrevolucionario - a partir de Cárdenas-y las transformaciones de las políticas sociales devendrán cambios en las políticas económicas. Entonces, en lugar de buscar un sistema de protección integral, se orienta, poco a poco, a la atención de necesidades específicas y a la creación de organismos gubernamentales que sirven solo para orientar el gasto de las diferentes instancias del Estado. Sobre el segundo bloque, es lo que todos sabemos, la generación de las llamadas políticas públicas "focalizadas", particularmente, las del combate a la pobreza. De estas, y más allá de las críticas consabidas sobre falta de transparencia, de rendición de cuentas, duplicidades, entre otras, y hasta las ideológicamente orientadas, como su uso permanente para fines electorales, el autor asienta la estocada perfecta para demostrar la falta de eficacia y eficiencia con el dato duro y afirma: "las cifras (...) ponen en tela de juicio la eficacia del PROGRESA-Oportunidades-PROSPERA, ya no se diga para combatir la pobreza, sino para proteger a la población más vulnerable en episodios de convulsión económica" (p. 145).

El tercer capítulo, La participación: análisis del concepto y vinculación con las políticas sociales, aborda una de esas palabras que hoy día parece no solo obligado citar para ser "políticamente correcto", sino que en el ámbito de las políticas públicas se ha convertido en un dogma, pero que — como señala Martínez - "no se ha interpretado con la complejidad inherente de los conceptos políticos, su instrumentación se ha reducido a acciones concretas como pasar lista o elegir representantes y ha sido una dimensión ausente en las evaluaciones" (de la contraportada). Además de registrar los

\section{6}


múltiples significados, destaca que es una de esas palabras que llaman a la legitimidad, por lo que recibe (no menos múltiples) adjetivaciones. Entonces, resume sus hallazgos a tres núcleos conceptuales: a) la participación social, definida como el asociacionismo inmediato; b) la participación ciudadana, como la acción de ciudadanos con el propósito de influir en el poder público, y c) la participación política, que se define en tanto busca influencia en el poder constituido y constituyente.

A partir de esa base, se concentra en definir qué es la participación social en las políticas públicas, cuando se tiene como tarea inmediata coadyuvar a, o implementar, una acción pública del Estado. Identifica dos grandes paradigmas: la elección racional y el modelo estructural, de los que identifica cinco grandes teorías: dos para la elección racional - cognitiva y de los incentivos-, y tres para las estructurales — voluntarismo cívico, capital social, y de la justicia y la equidad social—; desde luego, cada una de estas teorías presenta diversos indicadores. Con la disciplina que caracteriza a nuestro autor, esa revisión no es ociosa, se trata de la base para construir su modelo de participación para el estudio de caso.

El acápite titulado La participación en el programa de comedores comunitarios es una buena muestra de cómo se debe documentar una investigación. No sé que le hayan dicho al autor acerca de su talante como politólogo, pero este capítulo me ha convencido de que es un buen antropólogo. No solo trata y muestra el contexto relevante del derecho a la alimentación, sino también da cuenta de las negociaciones, los avatares y las relaciones en el diseño del programa y para el establecimiento de los comedores comunitarios. Sumado a ello, hay amplias referencias al trabajo de campo, citas a entrevistas e interpretaciones al más puro estilo vareliano acerca de los conocimientos y la información, los sentires, las normas y valoraciones, así 
como de las expectativas de los diversos agentes sociales involucrados en la implementación del programa.

A partir de ello, aborda la dimensión de interés: la participación; es decir, los mecanismos de coordinación que se establecen en torno a los comedores: comités comunitarios, la contraloría social y los comités que se forman. Regalo dos perlas para que los lectores se hagan, ya sea unas mancuernillas ya unos aretes, como motivación para leer este libro:

1. Un primer hallazgo por destacar es lo que podría denominar la influencia del poder político (...) la instalación de los comedores comunitarios dependió ampliamente de las negociaciones para la aceptación del programa social, primero, por los gobernadores del Estado y, posteriormente, por las comunidades (p. 290).

2. La "alianza político-cultural entre los promotores comunitarios y las comunidades se percibió en las visitas a los comedores [...un promotor dice] nos organizamos bien, todos opinamos e intercambiamos ideas para que funcionen las cosas (p. 326).

Con esto invito al lector a que imagine la rica documentación que Manuel I. Martínez pone a nuestra disposición en el libro. Y, bueno, como también tenemos prácticas político-culturales, les doy el pilón: documenta cómo se pretende usar el espacio de los comedores comunitarios para otros proyectos, como las granjas de postura.

Para ir cerrando, las conclusiones: [intituladas] Apuntes sobre el fenómeno de la participación, las instituciones y la necesaria reformulación de la política social en México, nos advierten, a través del título, que el autor ha vuelto sobre la senda de la politología, aunque en realidad comienza con una viñeta etnográfica que nos relata su llegada al comedor de San Sebastián, en el municipio de Bachajón. 
Después del guiño engañoso, desvela su opción preferencial por las teorías del capital social para este análisis, ya que afirma: "Los comedores comunitarios son un territorio participativo donde se ponen en práctica valores y habilidades, se recrean relaciones sociales y se fortalecen códigos de confianza" (p. 356). Aunque después de haber realizado la amplia revisión hubiese sido una broma de mal gusto presentar al lector su vasto análisis teórico.

Desde luego que no es así, vuelve sobre sus pasos para no quedarse con la pura idea de los mecanismos de coordinación —contraloría, comité de comunidad y coordinación regional-, y muestra que hay otras dimensiones y otros actores que influyen sobre el programa y su concreción en la comunidad. Señala los aspectos que, en su análisis de la participación para los casos seleccionados (en los siete indicadores identificados), se aproximan a, o son susceptibles de considerarse, reflexiones generalizables.

\section{Exhortación a la lectura}

Al terminar de leer este libro siento pena. Aclaro: no por el contenido de este, sino por mí. Engallado y para elevar mi ego, advertí verbalmente al autor que sería sumamente crítico y encontraría sin piedad "los prietitos en el arroz". Y eso es sumamente complicado para un libro de fina manufactura como el que aquí comento.

No obstante, he de señalar que, si bien manifiesta algunas reflexiones generalizables, faltó puntualizar — como lo prometió- cómo lo llevan a readecuar el esquema de análisis. Y reitero que hay un capítulo que a mi parecer tiene un sustrato antropológico de gran relevancia y considero de "análisis al estilo vareliano". Aunque no puedo solicitar desandar los pasos, recomiendo para futuros trabajos del autor una revisión de la propuesta procesualista de la 
antropología política, a fin de complementar y enriquecer su perspectiva del capital social.

Sin duda, pues, es un libro que merece ser leído, comentado y utilizado en los procesos de formación de nuevos recursos humanos. $\varepsilon$ 